\title{
Study on correlation between combined femoral and acetabular anteversion in patients undergoing total hip arthroplasty using CT scan
}

\author{
Haris Murthy*, T. V. S. Reddy
}

\author{
${ }^{1}$ Department of Orthopedics, Raichur Institute of Medical Sciences, Raichur, India \\ ${ }^{2}$ Surxa Hospital, Kurnool, India
}

Received: 04 February 2016

Revised: 09 February 2016

Accepted: 27 February 2016

\author{
*Correspondence: \\ Dr. Haris Murthy, \\ E-mail: drharishmurthy@yahoo.co.in
}

Copyright: () the author(s), publisher and licensee Medip Academy. This is an open-access article distributed under the terms of the Creative Commons Attribution Non-Commercial License, which permits unrestricted non-commercial use, distribution, and reproduction in any medium, provided the original work is properly cited.

\begin{abstract}
Background: The concept of hip Arthroplasty started as a very simple rudimentary idea of excising the hip joint (excision Arthroplasty), through to fusion of the hip, to actual replacement of the joint surfaces with various artificial substances ranging from glass, plastic, pig's bladder, ivory, ceramic polyethylene (PE) and more recently to actual metal-on metal hip replacement. Hip replacement is usually considered only after other therapies, such as physical therapy and pain medications, have failed. To determine the combined femoral and acetabular anteversion in patients undergoing total hip arthroplasty using CT scan.

Methods: Patients admitted in hospital who underwent total hip arthroplasty from July 2013 to July 2015 were included in the study.

Results: The study comprised of 40 patients, there were $15(37.5 \%)$ females and $25(62.5 \%)$ males. There were $7(17.5 \%)$ patients with less than $30^{\circ}$ femoral component anteversion, $26(65 \%)$ patients were in the range of $30^{\circ}-50^{\circ}$ anteversion and $7(17.5 \%)$ patients were in the range of more than $50^{\circ}$ anteversion. There were $10(25 \%)$ patients with less than $40^{\circ}$ combined anteversion, $23(57.5 \%)$ patients were in the range of $40^{\circ}-70^{\circ}$ anteversion and $7(17.5 \%)$ patients were in the range of more than $70^{\circ}$ anteversion.

Conclusions: The functional outcome of the patients was better when the combined anteversion was between 4-7ff as compared to the functional outcome when the combined anteversion was either less than 40 " or more than 70". However, we required larger group of study to validate the findings.
\end{abstract}

Keywords: Hip joint, Anteversion, CT scan

\section{INTRODUCTION}

Total Hip Arthroplasty (THA) is one of the most common procedures performed on Orthopaedic elective lists, and is considered to be one of the best medical innovations of our generation. ${ }^{1}$ The concept of hip Arthroplasty started as a very simple rudimentary idea of excising the hip joint (excision Arthroplasty), through to fusion of the hip, to actual replacement of the joint surfaces with various artificial substances ranging from glass, plastic, pig's bladder, ivory, ceramic polyethylene
(PE) and more recently to actual metal-on metal hip replacement. $^{2}$ There has been a dramatic rise in experimentation with these various elements as a result of the growing human population and the increased diagnosis of arthritides and other hip pathologies, with sometimes disastrous consequences for the patient'. In addition to that, there is also a recent growing increase in arthroplasties for hip fractures in fit elderly people, in many developed countries like the UK as a result of the NICE (National Institute for Clinical Excellence) guidelines and increased quality of life among the 
growing elderly population. However, there is a lot of knowledge and good evidence which has emanated from the recent improvement in the techniques and implants used for THA, which provided very good results and outcomes, as well as changing the life of many individuals afflicted with various types of arthritis. Hip replacement has been acclaimed to be a very satisfying operation for patients, with very good long term outcomes in many cases, but new problems and challenges are being constantly observed in many hip registries, as a result of the longevity of the prosthetic implants and the improved quality of healthcare in many developed countries; which leads to increased life expectancy of the individuals; therefore giving more time for the implants to last and perhaps reveal their weaknesses'. Rudimentary efforts have been documented throughout the history of hip replacement surgery from as early as the 17 th century. Among the more daring were the experimental uses of materials implemented such as: celluloid, silver plates, rubber struts, magnesium, zinc, glass, pyres, decalcified bones, wax, muscle tissue and celluloid. There was no long term success stories achieved whilst experimenting with these materials as the body almost always reacted against them. These materials were also unable to cope with the stress of supporting body weight for long periods of time. These early experimental days did however start paving the way for surgeons' successful attempts at hip replacement surgery. Throughout the early days of prosthesis surgery, most operations were performed to replace only one of the joints and through the experimental years there was also risk of infection that was inherent before the advent of antibiotics.

The use of artificial hips was slowly becoming better known within medical circles by the 1930s, though it was still rare for someone to undergo hip replacement surgery throughout this period. There were also experimental attempts to replace joints with Teflon, which seemed like a good idea at the time, but the Teflon prosthesis itself normally wore out within two to three years, or eventually caused patients to suffer osteolysis, which is where the bone starts to dissolve and be reabsorbed by the body. Even though these first hip replacement surgeries seemed rudimentary, they were considered to be a better alternative than the crippling and severe pain that was endured by people suffering arthritis. One of the major problems with the experimental materials was that the articulating surfaces inserted in the joints.' were unable to be naturally lubricated by the body which made them to wear each other down and eventually loosen: making it necessary to replace the joints again by performing revision surgery. Artificial joints were eventually being manufactured from steel or chrome which had a much better 'hip life' due to the materials superior strength non corrosive quality.

First performed in 1960, hip replacement surgery is one of the most successful operations in all of medicine '. Since 1960, improvements in joint replacement surgical techniques and technology have greatly increased the effectiveness of total hip replacement. According to the Agency for Healthcare Research and Quality, more than 285,000 total hip replacements are performed each year in the United States.

In a total hip replacement surgery, the painful parts of the damaged hip are replaced with prosthesis, a device that substitutes a joint. The prosthesis consists of metal components: a socket (cup), head, and stem. The outer shell of the socket (cup) is usually made of metal and the inner shell consists of plastic, or ceramic: or the entire socket (cup) may be plastic.

The aims of the procedure are pain relief and improvement in hip function. Hip replacement is usually considered only after other therapies, such as physical therapy and pain medications, have failed.

The major potential intraoperative complications were fracture, nerve injury, vascular injury, cement-related hypotension, dislocation, aseptic acetabular and femoral stem loosening, peri-prosthetic fractures, and infection etc.

Presently the types of prosthesis used for total hip replacement are:

1. Metal-on-Polyethylene (M-on-PE): Metal-onpolyethylene bearings are the most widely used and rigorously followed up of all the prostheses, making up the majority of THA undertaken in India today. The main concern for M-on-PE prosthesis is $\mathrm{PE}$ debris which creates periprosthetic osteolysis by the release of cytokines and roteolytic enzymes ultimately leading to implant failure. ${ }^{3}$

2. Metal-on-Metal: Metal-on-metal (M-on-M) prostheses are expenence a revival after falling out of favor in the 1970's. Prosthetic wear in M-on-M has been reported to be 60 times less than expected with conventional M-on-PE prostheses.

The objective of the study was to determine the combined femoral and acetabular anteversion in patients undergoing total hip arthroplasty using CT scan.

\section{METHODS}

Patients admitted in hospital who underwent total hip arthroplasty from July 2013 to June 2015 were included in the study. Patients who underwent bilateral total hip arthroplasty for osteonecrosis of femoral head and who underwent unilateral total hip arthroplasty for fracture neck femur or osteonecrosis of femoral head were included in the study. Whereas, patients with bilateral disease of the hip in varied stages, with developmental dysplasia of hip, with fractures of acetabulum and lower limb long bones, and with bilateral disease who 
underwent unilateral total hip arthroplasty were excluded in the study.

For the present study, the sample size 40 was taken and samples are selected by simple random sampling method. Clinical diagnosis of hip arthritis secondary to avascular necrosis of femoral head or due to non-union neck femur fracture was done with limitation of range of movements, supratrochanteric softening and gait analysis. Treatment in the form of analgesics was given for pain relief. Anteroposterior X-ray of pelvis with both hips in 15 degree intemal rotation and lateral view of the affected joint were taken. The pre-operative Acetabular cup diameter, LCD and angulation of acetabulum were calculated with the help of the radiographs of the normal opposite hip. Affected limb was kept in a Thomas' splint with skin traction with adequate splintage to correct flexion deformity if any and to prevent overriding whenever present in cases of non-union neck femur fracture. Preoperative routine blood and urine investigations were done. Informed consent was obtained by patient for both the surgical procedure and participation in the study.

\section{Computed tomographic measurement of acetabular and femoral component version}

All the evaluations were done by a single radiologist well versed with the calculation of combined anteversion to prevent inter-observer variability. CT SCAN MACHINE used Siemens somatum. $(64 \times 2)$ slice mulltidetector CT scan machine with CPT software (Siemens, Germany). Each patient underwent a pelvic CT examination 15days after surgery, and version angles of the acetabular and femoral components were measured. We defined acetabular component version as the angle between a line connecting the lateral anterior and posterior margins of the acetabular component and the sagittal plane defined as the plane perpendicular to a line connecting two identical points on either side of the pelvis. Femoral component version was calculated as the angle between a line from the centre of the femoral head to the centre of the neck of femoral prosthesis, and a line connecting the posterior aspect of the medial and lateral femoral condyles, respectively. Combined anteversion was calculated as sum of femoral and acetabular anteversion.

\section{Statistical analysis}

Descriptive statistics such as mean, SD and percentage was used. Data analysis was done by using MS-Excel.

\section{RESULTS}

This is prospective study design. The study comprised of 44 patients as per the inclusion criteria. Of the 44 patients, there were 17 (39\%) females and $27(61 \%)$ males. The youngest patient in our series was 15 years and the oldest was 70 years. Out of the 44 patients, 2 expired during the follow-up due to unrelated causes and 2 patients were lost in follow-up. The remaining 40 patients were followed up for an average of 3 months. Out of the 40 followed up patients, 25 were male $(62.5 \%)$ and $15(37.5 \%)$ were female. 20 male patients were operated for AVN and 5 male patients were operated for ICNF. Among the female patients, 10 were operated for AVN and 5 were operated for ICNF (AVN 30 patients and ICNF 10 patients).

Out of the 40 patients enrolled in the study, 30 patients were operated for osteonecrosis of femoral head (20 males and 10 females) and 10 were operated for fracture non-union neck femur with secondary osteoarthritis of hip (5 males and 5 females). In present study, majority of patients were belongs to in the age group of 51-60 (25\%) followed by $21-30,31-40$ (20\% each) and 61-70 (17.5\%) (Table 1).

Table 1: Age wise distribution of patients.

\begin{tabular}{|ll|}
\hline Age Group & No of Patients \\
\hline $11-20$ & 2 \\
\hline $21-30$ & 8 \\
\hline $31-40$ & 8 \\
\hline $41-50$ & 5 \\
\hline $51-60$ & 10 \\
\hline $61-70$ & 7 \\
\hline
\end{tabular}

Table 2: Mean and standard deviation of femoral component anteversion range.

\begin{tabular}{|lllll|}
\hline $\begin{array}{l}\text { Femoral } \\
\text { component } \\
\text { anteversion } \\
\text { range }\end{array}$ & Number & $\%$ & Mean & $\begin{array}{l}\text { Standard } \\
\text { Deviation }\end{array}$ \\
\hline$<30^{\circ}$ & 7 & 17.5 & 18.0 & 4.7 \\
\hline $30^{\circ}-50^{\circ}$ & 26 & 65 & 34.2 & 7.0 \\
\hline$>50^{\circ}$ & 7 & 17.5 & 54.3 & 1.8 \\
\hline
\end{tabular}

Table 3: Mean and standard deviation of acetabular component anteversion range.

\begin{tabular}{|lcccc|}
\hline $\begin{array}{l}\text { Femoral } \\
\text { component } \\
\text { anteversion } \\
\text { range }\end{array}$ & Number & $\%$ & Mean & $\begin{array}{l}\text { Standard } \\
\text { Deviation }\end{array}$ \\
\hline$<20^{\circ}$ & 12 & 30 & 15.0 & 7.8 \\
\hline $20^{\circ}-30^{\circ}$ & 16 & 40 & 24.3 & 6.3 \\
\hline$>30^{\circ}$ & 12 & 30 & 34.1 & 12.4 \\
\hline
\end{tabular}

Table 4: Mean and standard deviation of combined anteversion range.

\begin{tabular}{|lcccc|}
\hline $\begin{array}{l}\text { Femoral } \\
\text { component } \\
\text { anteversion } \\
\text { range }\end{array}$ & Number & $\%$ & Mean & $\begin{array}{l}\text { Standard } \\
\text { Deviation }\end{array}$ \\
\hline$<40^{\circ}$ & 10 & 25 & 32.3 & 10.8 \\
\hline $40^{\circ}-70^{\circ}$ & 23 & 57.5 & 61.8 & 3.7 \\
\hline$>70^{\circ}$ & 7 & 17.5 & 89.9 & 21.9 \\
\hline
\end{tabular}


The femoral anteversion calculated from the postoperative CT scan ranged from $10.1^{\circ}$ anteversion to $56.5^{\circ}$ anteversion with a mean of $34.9^{\circ} \pm 9.5^{\circ}$. The femoral anteversion was divided into 3 groups:

1. Less than $30^{\circ}$ anteversion

2. $30^{\circ}-50^{\circ}$ anteversion

3. More than $50^{\circ}$ anteversion

There were $7(17.5 \%)$ patients with less than $30^{\circ}$ femoral component anteversion, $26(65 \%)$ patients were in the range of $30^{\circ}-50^{\circ}$ anteversion and $7(17.5 \%)$ patients were in the range of more than $50^{\circ}$ anteversion (Table 2).

The acetabular anteversion calculated from the postoperative CT scan ranged from $12.4^{\circ}$ anteversion to $37.4^{\circ}$ anteversion with a mean of $25.1^{\circ} \pm 6.7^{\circ}$. The acetabular anteversion was divided into 3 groups:

1. Less than $20^{\circ}$ Anteversion

2. $20^{\circ}-30^{\circ}$ Anteversion

3. More than $30^{\circ}$ Anteversion

There were $12(30 \%)$ patients with less than $20^{\circ}$ acetabular component anteversion, $16(40 \%)$ patients were in the range of $20^{\circ}-30^{\circ}$ anteversion and $12(30 \%)$ patients were in the range of more than $30^{\circ}$ anteversion (Table 3).

The Combined anteversion calculated by adding femoral anteversion and acetabular anteversion ranged from $25.5^{\circ}$ anteversion to $93.9^{\circ}$ anteversion with a mean of $59.3^{\circ} \pm 15.7^{\circ}$. The acetabular anteversion was divided into 3 groups.

1. Less than $40^{\circ}$ anteversion

2. $40^{\circ}-70^{\circ}$ anteversion

3. More than $70^{\circ}$ anteversion

There were $10(25 \%)$ patients with less than $40^{\circ}$ combined anteversion, $23(57.5 \%)$ patients were in the range of $40^{\circ}-70^{\circ}$ anteversion and $7(17.5 \%)$ patients were in the range of more than $70^{\circ}$ anteversion. (Table-4)

\section{DISCUSSION}

Accurate placement of the acetabular and femoral components during total hip arthroplasty (THA) is critical to ensure a successful outcome. To avoid complications, the components should be implanted in a defined safe range, but great variations have been reported for the components' orientation. Optimal position has been studied by many authors, and the combined version of the components is important to avoid impingement and/or dislocations. However, there is little published information based on actual measurements of component alignment in THA, and only one study has compared the component version angles with the native version angles. ${ }^{4}$
Only $71 \%$ of femoral and $45 \%$ of acetabular components were within the expected clinical version range. The intraoperative assessment of component version in THA is often inaccurate. Their results indicated that both the CT measurements and the surgeons' estimations for acetabular and femoral component version were found to be higher for the posterior approach. ${ }^{5}$

Maheshwari AV et al calculated Femoral neck anteversion, acetabular anteversion and combined anteversion in the normal Indian adult population. ${ }^{6}$ When compared with the Westem data, the femoral neck anteversion values were $3-12^{\circ}$ lower and the combined anteversion values were $3-5^{\circ}$ lower in Indian adults. The acetabular anteversion values were comparable, but were skewed towards the higher side.

According to Takaaki et al, the component version was significantly greater than the native version in both acetabular and femoral version. ${ }^{7}$

There was a significant correlation between the stem and native femoral versions, but not between the acetabular component and native acetabular versions.

Our study demonstrated that the femoral anteversion was as following. The femoral anteversion calculated from the post-operative CT scan ranged from 10.1" anteversion to 56.f anteversion with a mean of $34.9+9$.f. There were 7 $(17.5 \%)$ patients with less than 30 femoral component anteversion with mean of 18.0, $26(65 \%)$ patients were in the range of 30-5Oanteversion with mean of 34.T and $(17.5 \%)$ patients were in the range of more than 50anteversion with mean of 54.3.

Our results were consistent with the study ${ }^{7}$. According to their study, the femoral component version as measured from the CT scan ranged from $0.2^{\circ}$ to $72.0^{\circ}$ of anteversion with a mean of 40.3" + 11.3". The anteversion was less than $20^{\circ}$ in $57(4.07 \mathrm{o})$ stems, $20^{\circ}$ $30^{\circ}$ in $177(12.5 \%)$ stems, 30'-40" in 428 (30.3\%) stems, $40^{\prime}-50$ ' in $491(34.8 \%)$ stems, and greater than 50 " in 258 (18.3\%) stems.

The acetabular anteversion calculated from the postoperative CT scan ranged from 12.4 anteversion to 37.4 anteversion with a mean of $25.1 "+6.7$. There were 12 $(30 \%)$ patients with less than $2 \mathrm{U}$ acetabular component anteversion with mean of $15.0,16(40 \%)$ patients were in the range of $2 \mathrm{U}-30$ anteversion with mean of 24.1 and 12 (30\%) patients were in the range of more than 30 anteversion with mean of $34.1^{\circ}$.

Our results were consistent with the study. ${ }^{7}$ According to their study, the acetabular component version angles ranged from 22.7" of retroversion to 56.6' of anteversion with a mean of $24.7 "+11.3 "$. The anteversion u'as less than $10^{\prime \prime}$ in $135(9.6 \%)$ cups, 10o-20o in $271(19.2 \%)$ cups, $20^{\circ}-30^{\circ}$ in $553(39.2 \%)$ cups, $20^{\circ}-40^{\prime}$ in 367 $(26.0 \%)$ cups, and greater than $40^{\circ}$ in $85(6.0 \%)$ cups. 
The combined anteversion calculated by adding femoral anteversion and acetabular anteversion ranged from 25.f anteversion to 3.9 anteversion with a mean of 59.T+15.7. There were $10(25 \%)$ patients with less than 4Ocombined anteversion with mean of 32 ! $23(57.5 \%)$ patients were in the range of $40-70$ anteversion with mean of 61.8 and $7(17.5 \%)$ patients were in the range of more than 70 anteversion with mean of 89.9 .

Our results were consistent with the study ${ }^{7}$. According to their study, the combined version of the components ranged from 12.9 to 112 " of anteversion with a mean of $65.0^{\prime}+15.7^{\prime \prime}$. The anteversion was less than 40'in 98 (6.9 $\%$ ) hips, $40^{\prime \prime}-45^{\circ}$ in $120(8.5 \%)$ hips, 50"-60" in 271(19.2 $\%)$ hips, $60^{\circ}-70^{\circ}$ in $375(26.6 \%)$ hips,70"-80'in 322 $(22.8 \%)$ hips, and greater than $80^{\prime}$ in $225(15.9 \%)$ hips.

According to Lewinnek GE et al, Cup abduction of $40^{\circ}+$ $10^{\circ}$ is considered to be the "safe zone" of lower dislocation risk. ${ }^{8}$ Cup anteversion should be $20^{\circ} \pm 5^{\circ}$. Outside this safe range, dislocation in one study increased fourfold $(6.1 \%$ versus $1.5 \% ; \mathrm{P}<0.05)$

The dislocation rate for cup orientation with anteversion of $15^{\prime} \mathrm{t} 10^{\prime \prime}$ and lateral opening of $40^{\prime \prime}+10^{\circ}$ was 1.5 per cent, while outside this "safe" range the dislocation rate was 6.1 per cent. It was found that anterior dislocations were associated with increased acetabular-component anteversion. There was no significant correlation between cup-orientation angle and posterior dislocation.

In our study, 19 cups had anteversion more than the upper limit of the safe range proposed by Lewinnek GE and 6 cups had anteversion less than lower limit. Two cases out of nineteen $(10.52 \%)$ outside the safe range with acetabular anteversion more than 30' (35.4 and 37.\$ had anterior dislocation, one at 2 weeks post-operatively and the other one 4 weeks post-operatively. These 2 cases, eventually required revision of the cup at a later date. Out of the six cases with anteversion less than if of anteversion none had any dislocation.

\section{CONCLUSION}

The present study of 40 patients was operated for total hip arthroplasty (THA). All the patients were operated by posterolateral approach. The combined anteversion was calculated as the sum of acetabular and femoral anteversion using a CT scan. The patients were followed up for a period of 3 months after the surgery.

From this study, the functional outcome of the patients was better when the combined anteversion was between 4-7ff as compared to the functional outcome when the combined anteversion was either less than 40 " or more than $70^{\prime}$. However, we required larger group of study to validate the findings.

Funding: No funding sources

Conflict of interest: None declared

Ethical approval: The study was approved by the Institutional Ethics Committee

\section{REFERENCES}

1. Knight SR, Aujla R, Biswas SP. Total Hip Arthroplasty - over 100 years of operative history. Orthopedic Reviews. 2011;3:el6.

2. Abdulkarim A, Prasad E, Nicola M, Tom F, John MO. Cemented versus uncemented fixation in total hip replacement: a systematic review and metaanalysis of randomized controlled trials. Orthopedic Reviews. 2013;5:e8.

3. BizotP, Nizard R, Hamadouche M. Prevention of wear and osteolysis: alumina-on-alumina bearing. Clin Orthop Relat Res. 2001;393:85-93.

4. Reikeris O, Gunderson RB. Components anteversion in primary cementless THA using snaight stem and hemispherical cup: A prospective study in 91 hips using CT-scan measurements. Orthop Traumatol Surg Res. 2006;97(6):615-21.

5. Wines AP, McNicol D. Computed tomography measurement of the accuracy of component version in total hip arthroplasty. J Arthroplasty. 2006;2r(5):696-701.

6. Maheshwari AV, Zlowodzki MP, Siram G. Femoral neck anteversion, acetabular anteversion and combined anteversion in the normal Indian adurt popuration: A computed tomographic study. Indian Journal of orthopaedics. 2010;44(3),277182.

7. Fujishiro $\mathrm{T}$, Hayashi $\mathrm{S}$, Kanzaki $\mathrm{N}$, Kanno $\mathrm{T}$. Computed tomographic measurement of acetabular and femoral component version in total hip arthroplasty. Int Orthop. 2014;38(5):941-6.

8. Lewinnek GE, Lewis JL, Tan R, Compere CL, Zimmerman JR. Disrocations after total hipreplacement arthroplasties. J Bone Joint surg Am. 1978:60:21710.

Cite this article as: Murthy $\mathrm{H}$, Reddy TVS. Study on correlation between combined femoral and acetabular anteversion in patients undergoing total hip arthroplasty using CT scan. Int J Res Orthop 2016;2:13-7. 